\title{
When to Suspect a Diagnosis of Amyloidosis
}

\author{
Iuliana Vaxman ${ }^{\mathrm{a}-\mathrm{c}} \quad$ Morie Gertz ${ }^{\mathrm{a}}$ \\ ${ }^{a}$ Division of Hematology, Mayo Clinic, Rochester, MN, USA; ${ }^{b}$ Institute of Hematology, Davidoff Cancer Center, \\ Rabin Medical Center Petah-Tikva, Petah-Tikva, Israel; ' Israel Sackler Faculty of Medicine, Tel-Aviv University, \\ Tel-Aviv, Israel
}

\section{Keywords \\ AL amyloidosis · ATTR amyloidosis · Misdiagnosis}

\begin{abstract}
Amyloidosis is a group of complex diseases caused by extracellular deposition of pathological insoluble fibrillary protein in organs and tissues and may result in severe organ dysfunction. Despite the etiological heterogeneity of systemic amyloidosis, the clinical manifestations of the different forms of amyloidosis largely overlap and depend upon the effected organ. The signs and symptoms that should raise suspicion for the potential diagnosis of amyloidosis are usually nonspecific; therefore, establishing the diagnosis is difficult, and early diagnosis requires clinical suspicion. Light chain ( $A L)$ amyloidosis may present with highly specific signs such as macroglossia and periorbital purpura, but these signs are insensitive. Amyloidosis is still underdiagnosed, even though treatments are now available and are effective in improving patient's survival and quality of life. Cardiac amyloidosis is the major determinant of survival, and the earlier it is detected the better the survival. All MGUS patients should be routinely screened for AL amyloidosis by a focused history and physical examination and routine assessment of urine albumin. The aim of this review is to provide
\end{abstract}

clinicians with knowledge about the signs and symptoms that raise the suspicion of amyloidosis, bearing in mind the importance of early diagnosis of this disease.

(c) 2020 S. Karger AG, Basel

\section{Case 1}

A 52-year-old male, previously healthy, first noticed fatigue in January 2019. In June 2019, he developed abdominal pain and was diagnosed with pancreatitis. In May 2019, he noticed a significant decrease in stamina and was unable to climb 15 stairs without stopping. Blood test showed an elevated alkaline phosphatase (ALP) of 282 U/L (normal level <109). Transaminases were normal. He underwent coronary angiography which was negative and an endomyocardial biopsy was not preformed. In December 2019, he was re-admitted due to abdominal pain. At this point he had lost $25 \mathrm{~kg}$ over a period of 10 months. As part of the evaluation of his abdominal pain, he underwent a urinalysis that showed proteinuria and in a 24-h urine collection, he had $500 \mathrm{mg}$ of protein, mainly albumin. He received a course of dexamethasone and underwent a renal biopsy, which was complicated by intra-abdominal bleeding with a need for transfusions. The biopsy showed amyloid deposits that were confirmed by mass spectroscopic analysis as $\mathrm{AL}$ amyloidosis. Lambda light chain level was $8.6 \mathrm{mg} / \mathrm{dL}$ and bone marrow biopsy showed $30 \%$ monoclonal plasma cells. NT pro BNP was $863 \mathrm{pg} / \mathrm{mL}$, and troponin was $<6 \mathrm{ng} / \mathrm{L}$. Echocardiography showed septal thickness of $17 \mathrm{~mm}$, and cardiac MRI demonstrated thickening of the ventricular walls with late gadolinium enhancement. He was also found to have factor $\mathrm{X}$ and factor $\mathrm{V}$ karger@karger.com

www.karger.com/aha

Karger $\stackrel{2}{=}$ (c) 2020 S. Karger AG, Base

(

Dr. Morie Gertz, MD, MACP

Mayo Clinic

200 First Street SW

Rochester, MN 55905 (USA)

gertz.morie@mayo.edu 
deficiencies, consistent with liver involvement of amyloidosis. Blood smear showed Howell bodies compatible with hyposplenism. Liver was not enlarged in a CT scan. Bortezomib $1.3 \mathrm{mg} / \mathrm{m}^{2}$ once weekly, oral cyclophosphamide, and dexamethasone $20 \mathrm{mg} /$ week was initiated.

\section{Comment}

Had amyloidosis been suspected, the pathological diagnosis could have been confirmed with a fat pad biopsy, and the kidney biopsy with associated hemorrhage could have been avoided. Although this patient fits the eligibility criteria for ASCT, it was not offered because he was severely malnourished and deconditioned, rendering him ineligible for ASCT.

\section{Case 2}

A 61-year-old male presented in March 2018 with fatigue, periorbital swelling, leg edema up to the groin level, and lymphadenopathy. He underwent a CT scan that showed mildly enlarged lymph nodes in the retroperitoneal and pelvic region, the largest of which was $16 \mathrm{~mm}$ and an enlarged liver. Albumin level was $1.5 \mathrm{~g} / \mathrm{dL}$ and ALP was 135 U/L. In August 2018, he had a follow-up CT scan that showed the enlarged lymph-nodes, and in September 2018 he underwent a biopsy of a lymph node in his right groin. The biopsy demonstrated amyloid deposition by Congo red stain and involvement with kappa light chain restricted plasma cells. Typing with mass spectrometry confirmed the diagnosis of AL amyloidosis. Kappa at that time was $2.75 \mathrm{mg} / \mathrm{dL}$. $24 \mathrm{~h}$ urine protein was $15,561 \mathrm{mg}$ with no measurable monoclonal protein in the urine. Troponin $\mathrm{T}$ was $30 \mathrm{ng} / \mathrm{L}(\mathrm{nL}<15)$ and NTproBNP was $989 \mathrm{pg} / \mathrm{mL}$ (normal level $<90$ ). Bone marrow biopsy showed $60-70 \%$ of bone marrow replaced by pink amorphous material and a small population of lymphoplasmacytoid lymphocytes. MYD88 was mutated. On October 2018 , the patient started treatment with rituximab, bortezomib, and dexamethasone. In March 2019, the patient underwent an autologous stem cell transplant with BEAM conditioning. During the transplant, he developed anasarca with a very significant rise in ALP up to $1,400 \mathrm{U} / \mathrm{L}$. The patient became progressively malnourished. Liver biopsy showed extensive amyloid deposits in the sinusoidal space and portal tracts. Endoscopy showed no significant macroscopic findings, but biopsies did demonstrate scant amyloid deposition in the submucosa and vessel walls on Congo red stain. The patient died at day 90 post-transplant due to pneumonia.

\section{Comment}

In amyloidosis, liver involvement can cause severe weight loss; these patients can have a significant deterioration in their liver function during transplant, and ASCT carries significant risks in AL amyloidosis, even if the patient fulfills published eligibility criteria.

\section{Background}

Amyloidosis is a disease caused by aggregates of misfolded proteins called amyloidogenic proteins [1]. Thirty-six proteins can cause these extracellular depositions of amyloid, resulting in damage to cells and organs. The deposits may precipitate at the location where they were synthesized, resulting in localized amyloidosis, like Alzheimer's disease. Fourteen proteins can cause systemic amyloidosis [2], where the defective protein can deposit distant from the place it was produced, like TTR (prealbumin) that is produced in the liver or immunoglobulin light chains that are produced in the bone marrow.

Despite differences in structure and function, amyloid fibrils formed by all protein subunits form a $\beta$-pleated sheet structure [1] that stains with Congo red and is demonstrated under polarized light green birefringence. Congo red positivity is mandatory for the diagnosis of $\mathrm{AL} \mathrm{am}$ yloidosis [3]; however, biopsy is not necessary for the diagnosis of cardiac ATTR amyloidosis [4].

The most common types of systemic amyloidosis are immunoglobulin light chain (AL), mutant transthyretin (mATTR) or wild-type transthyretin (wtATTR), reactive (AA), fibrinogen (AFib), and apolipoprotein A-I (AApoAI) [5]. Systemic amyloidosis can be hereditary or acquired. AL amyloidosis and wtATTR amyloidosis are both acquired systemic amyloidosis.

The most common type of systemic amyloidosis is $\mathrm{AL}$ amyloidosis, with a reported incidence of 9-14 cases per million-person years in the USA [6]. Due to underdiagnosis of amyloidosis, it is reasonable to speculate that the prevalence may be higher. Data about the changes in prevalence of $\mathrm{AL}$ amyloidosis during the years are conflicting. A report from Mayo Clinic showed that the incidence of AL amyloidosis in Olmsted County, Minnesota, was 1.2 per 100,000 person-years and remained stable between 1990 and 2015 [7]. In contrast, a study using a claims database reported an increased prevalence between 2007 and 2015 [8]. The incidence of AL amyloidosis and ATTR amyloidosis rises with age [8].

Unlike multiple myeloma, morbidity and mortality in $\mathrm{AL}$ amyloidosis are not caused by the proliferation of monoclonal plasma cells but are caused by the effects of the toxic monoclonal protein, with cardiac function being the most important determinate of survival $[9,10]$. The hallmark of systemic AL amyloidosis is an underling plasma cell that secretes light chains that deposit in the target organs. However, in less than $2 \%$ of AL amyloidosis patients [11], routine laboratory testing is not sensitive enough to detect the light chains, or the light chain burden is very low, and the values are very close to the upper limit of normal $[12,13]$. These rare cases pose a great diagnostic challenge.

ATTR amyloidosis is a systemic progressive amyloidosis that can be divided into two subtypes: ATTRm that is an autosomal dominant inherited disease in which there 
Table 1. Diagnostic clues for AL amyloidosis

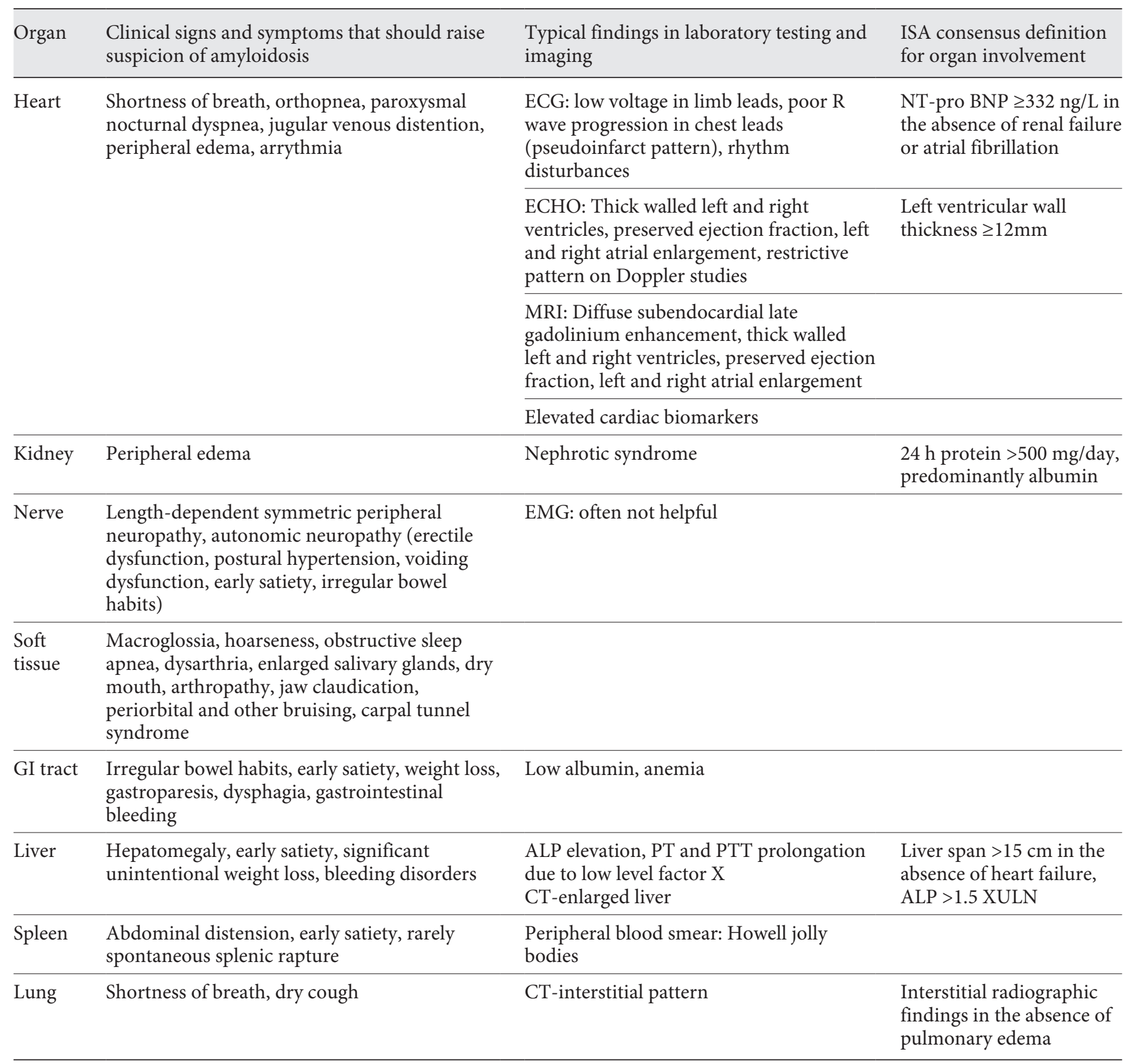

is a replacement of a single amino acid in the protein [1], and ATTRwt (previously named senile amyloidosis) caused by an intrinsic propensity to assume a pathological conformation that typically occurs in the elderly.

Delayed diagnosis is unfortunately common in amyloidosis [14], and efforts should be made to increase awareness, especially with the improved outcomes with treatment [15]. A published survey showed a significant delay in the diagnosis of amyloidosis, with a median time to diagnosis of 7 months. $37 \%$ of participants reported a delay in the diagnosis of over a year since symptoms started and over $10 \%$ were diagnosed more than 3 years after presentation. Multiple physician visits occurred before a diagnosis of amyloidosis was established [16]. Early awareness to the possibility that amyloidosis is the cause of organ dysfunction is also important because it can lead 
Table 2. The different systemic amyloidosis

\begin{tabular}{|c|c|c|}
\hline Disease & Cause & Affected organs \\
\hline Light chain amyloidosis & $\begin{array}{l}\text { Overproduction of amyloidogenic light chains by clonal plasma } \\
\text { cells in the bone marrow }\end{array}$ & $\begin{array}{l}\text { Heart, kidney, nerve, GI, liver, } \\
\text { soft tissue }\end{array}$ \\
\hline Heavy chain amyloidosis & $\begin{array}{l}\text { Overproduction of amyloidogenic heavy chains by clonal plasma } \\
\text { cells in the bone marrow }\end{array}$ & Heart, kidney, liver \\
\hline ATTRwt amyloidosis & Deposition of transthyretin & Heart, soft tissue, nerve \\
\hline ATTRm amyloidosis & Mutation in transthyretin & Heart, kidney, soft tissue, nerve \\
\hline AA amyloidosis & $\begin{array}{l}\text { Overproduction of serum amyloid A protein due to chronic } \\
\text { inflammation }\end{array}$ & Kidney, liver, spleen \\
\hline
\end{tabular}

to the use of surrogate site biopsies such as fat pad aspiration instead of organ biopsies that are riskier [15].

\section{Clinical Manifestations}

Amyloidosis is often named "The great imitator," because of the often nonspecific clinical picture at presentation [17]. The disease can present with a wide array of symptoms depending on the involved organ. Any organ may be involved, except for the brain parenchyma. The effected organs predominantly include: heart (70\%), kidney (60\%), peripheral $(15 \%)$ or autonomic nervous system (10\%), and gastrointestinal (15\%), liver (20\%), and soft tissue $(10 \%)[18,19]$. Approximately a third of the patients have only one affected organ, while most patients have several involved organs at presentation [19]. The most common clinical scenarios that should elicit suspicion for amyloidosis are non-diabetic nephrotic range proteinuria, cardiac failure with left ventricular hypertrophy in the absence of aortic stenosis or hypertension, peripheral or autonomic neuropathy without an obvious cause, chronic inflammatory demyelinating polyneuropathy with autonomic features, hepatomegaly with an elevated ALP and a normal appearance in imaging, macroglossia, and periorbital purpura. Table 1 summarizes the diagnostic clues that should raise the suspicion for amyloidosis.

ATTRwt patients are $90 \%$ male, usually have cardiac involvement without renal involvement, and $50 \%$ have a history of carpal tunnel syndrome (CTS) [20]. The finding of spontaneous rupture of the head of the biceps tendon should elicit the suspicion of ATTRwt amyloidosis [21] as well as spinal stenosis [22,23], and recurrent trigger finger [24]. When considering the diagnosis of amyloidosis, family history is of utmost importance. Table 2 summarizes the amyloid subtypes and their associated clinical phenotype.

Diagnosis of Amyloidosis

\section{Cardiac}

Amyloid heart disease is a restrictive cardiomyopathy manifesting as a disorder of diastolic failure. Fatigue, shortness of breath, orthopnea, paroxysmal nocturnal dyspnea, exercise intolerance, and peripheral edema are the presenting symptoms of cardiac amyloidosis and can also be seen in heart failure caused by other, more prevalent, etiologies, such as ischemic cardiomyopathy and aortic stenosis. The typical pseudo-infarct pattern on EKG [25] may lead to coronary angiography which is invariably negative (unless the patient also has a coincidental coronary artery disease). Low voltage in the EKG is seen in more than $50 \%$ of the patients with heart involvement [26]. The presentation can also include syncope, arrhythmia, sudden cardiac death, and rarely amyloid deposition in the coronary arterioles that can present as myocardial infarction $[27,28]$ or cardiogenic shock [29].

Echocardiography frequently shows thickening of the heart's walls, which may be misinterpreted as hypertrophic or hypertensive cardiomyopathy.

It should be noted that the classical granular sparkled appearance on echocardiography is not sensitive [30], so its absence does not exclude cardiac involvement. Global longitudinal strain has good accuracy in detecting cardiac involvement [31]. Diffuse subendocardial late gadolinium enhancement on cardiac magnetic resonance imaging is a sensitive marker for cardiac involvement, but its sensitivity is not $100 \%$, so a normal MRI does not exclude cardiac amyloidosis [32, 33]. Furthermore, imaging is unable to classify the type of amyloidosis.

Scintigraphy using pyrophosphate (PYP) or 3,3-diphosphono-1,2-propanodicarboxylic acid labeled with $99 \mathrm{mTc}$ is gaining increasing popularity and is an integral part of the diagnostic workup of ATTR amyloidosis, with $>99 \%$ sensitivity and $68 \%$ specificity [4]. These nuclear scans are widely available and noninvasive and are used to differentiate ATTR from AL amyloidosis. Grade 2 or 3 
positive scans exclude AL amyloidosis, and one should bear in mind that $30 \%$ of $\mathrm{AL}$ amyloidosis patients have weakly positive PYP scans [4]. Therefore, normal free light chain assays in the blood and negative immunofixation serum and urine are mandatory to exclude AL amyloidosis in the presence of a positive PYP scan. The combined finding of grade 2 or 3 Perugini score on scintigraphy and the absence of a monoclonal protein by IFE of serum and urine and normal sFLC measurements have $100 \%$ specificity for the presence of cardiac ATTR amyloid [4].

\section{Renal}

Foamy urine as the presenting symptom for renal involvement can be seen in the more prevalent nephropathy caused by diabetes mellitus or hypertension. Renal involvement may present as nonselective proteinuria above $500 \mathrm{mg} / 24 \mathrm{~h}$ [34] or a full-blown nephrotic syndrome. One third of the patients with amyloidosis have nephrotic syndrome that is manifested with a dramatic increase in the blood cholesterol level (median $270 \mathrm{mg}$ / $\mathrm{dL}$ ), so urinalysis looking for protein should be done in patients with a sudden increase in serum cholesterol levels. Enlarged kidneys are rarely seen in ultrasound or CT scan.

\section{Nervous System}

The peripheral neuropathy associated with amyloidosis typically begins in the lower extremities, is symmetrical and is manifested by tingling and numbness as well as pain. The clinical picture may be identical to diabetes-induced neuropathy, which is much more prevalent in the population. EMG may miss amyloid-induced neuropathy when only small fibers are involved [35], and in these cases, quantification of intraepidermal nerve fibers in a skin biopsy is recommend. The EMG finding of slow conduction with prolonged distal motor latencies may lead to a misdiagnosis of chronic inflammatory demyelinating polyneuropathy and treatment with IVIG and plasma exchange which are ineffective [36]. CTS occurs in 10-15\% of patients and may antedate the diagnosis of amyloidosis by a decade in ATTR amyloidosis [37] and AL amyloidosis. Unlike CTS caused by repetitive stress injury, in amyloidosis CTS is more likely to be bilateral and less likely to improve after release surgery. In a prospective trial that evaluated 98 patients, 10 patients had a positive Congo red staining of tenosynovial tissue [38]. This can potentially be an opportunity for early diagnosis of amyloidosis [39], especially if the CTS is bilateral.

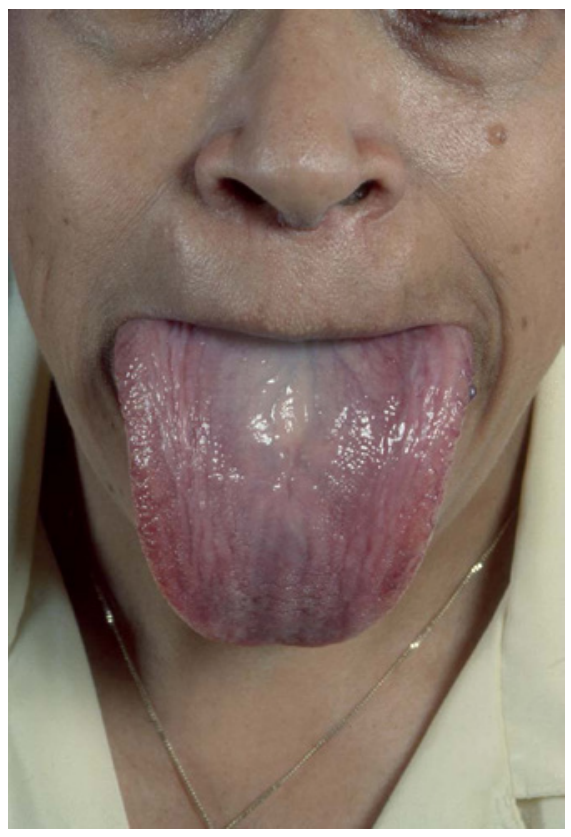

Fig. 1. Macroglossia.

Autonomic neuropathy may present with orthostatic hypotension that can also be seen from the diuretics used to treat peripheral edema present in renal or cardiac involvement. Dysmotility of the bowel can cause pseudoobstruction that can present as alternating constipation and diarrhea, and gastroparesis may cause recurrent emesis. Erectile dysfunction and xerostomia are prevalent, especially in elderly people, and are not diagnostic of autonomic involvement. Autonomic involvement does not necessarily need to be accompanied by peripheral neuropathy [40].

\section{Soft Tissue}

Macroglossia (Fig. 1) may be asymptomatic but may cause obstructive sleep apnea, altered taste sensation (dysgeusia), xerostomia, difficulty swallowing, resulting in anorexia [41]. On physical examination there are dental indentations sometimes only on the lower surface of the tongue, enlarged and stiff tongue on palpation and enlarged salivary glands. Macroglossia is not pathognomonic for amyloidosis and the differential includes hypothyroidism, tongue cancer as well as acromegaly. If the diagnosis of amyloidosis is confirmed, macroglossia is only seen in AL amyloidosis. Nail dystrophy may antedate the diagnosis of amyloidosis by years [42, 43]. Joint deposition of amyloid can cause joint pain and stiffness, and on physical examination the shoulder pad sign (Fig. 2) is a classical sign of amyloidosis [44]. 


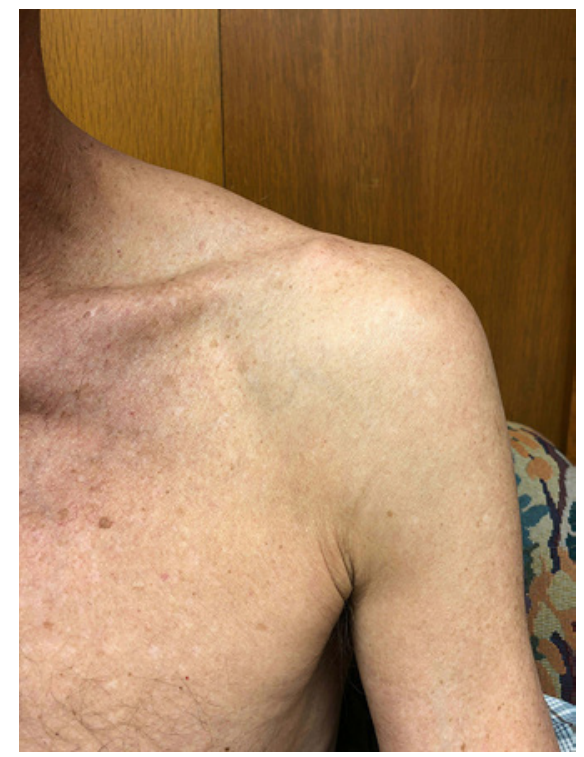

Fig. 2. Shoulder pad sign.

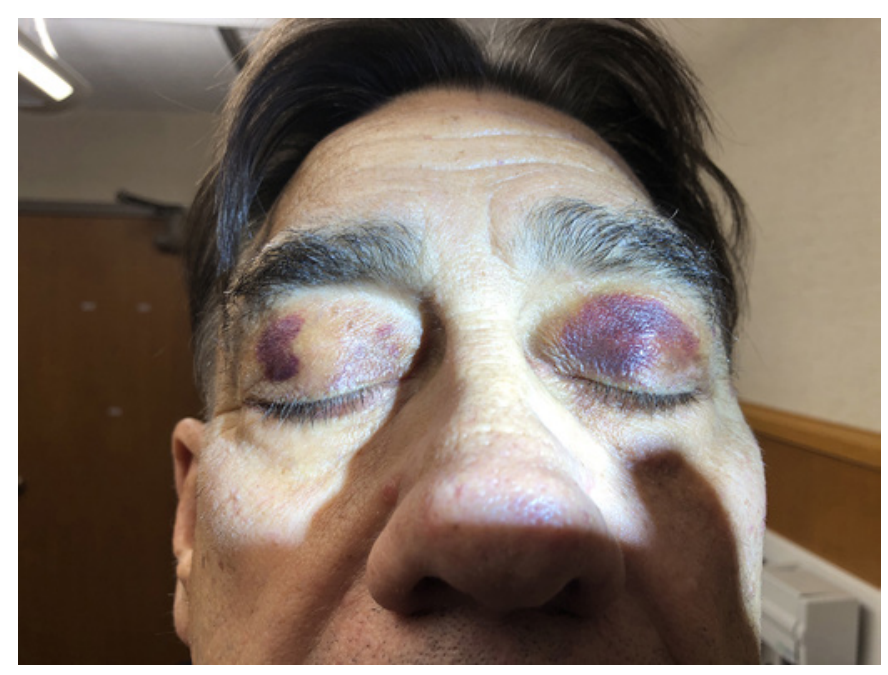

Fig. 3. Periorbital purpura.

Periorbital purpura (Fig. 3) is also a classical sign of AL amyloidosis and results from vascular fragility [45]. The patient may complain of bruising around one or both eyes, without anteceding trauma. The hematomas resolve even if no plasma cell-directed treatment is given. Small vessel disease may lead to claudication of jaw, calf, or buttock. Temporal artery involvement may be misdiagnosed as giant cell arteritis [46].

\section{Gastrointestinal and Liver}

It may be difficult to differentiate symptoms of autonomic neuropathy of the bowel from gastrointestinal in- volvement. Deposits may be asymptomatic or cause abdominal bloating [47], gastroparesis [48, 49], gastrointestinal bleeding $[50,51]$, weight loss, malabsorption, and dyspepsia.

Liver involvement typically presents as hepatomegaly and an increased ALP. Increased transaminase and bilirubin are late signs. Imaging shows homogenous enlargement of the liver. Significant weight loss is often seen, and the light chain involved is usually kappa. Liver involvement is often seen with concomitant renal involvement. Polyclonal hyper gammaglobulinemia suggests that another underling explanation for the abnormal liver enzymes should be sought.

\section{Other Manifestations of Amyloidosis}

Acquired deficiency of factor X may be associated with easy bruising and a severe bleeding diathesis [52], and this manifestation is specific for AL amyloidosis. PT/PTT (prothrombin time/partial thromboplastin time) are prolonged, and the low factor $\mathrm{X}$ levels are correctable by a mixing study [53]. Levels of factor X may rise with effective therapy. Other possible causes of increased risk of bleeding in AL amyloidosis are decreased synthesis of coagulation factors in advanced liver disease, amyloid infiltration of blood vessels [54], factor V deficiency [55], and acquired von Willebrand disease $[55,56]$.

Ocular morbidity is not limited to ATTRm amyloidosis, and was detected in $23 \%$ of patients with amyloidosis. It included vitreous opacities, keratitis, and corneal opacities [57].

\section{Localized Amyloidosis}

In localized amyloidosis, the typical sites of amyloid depositions are periorbital, nasopharyngeal or laryngeal [58-60], lungs or bronchi [61], lymph nodes, skin [6264], and gastrointestinal [65] and urinary tract $[66,67]$. Localized amyloidosis is usually not a life-threatening disease and rarely progresses to systemic amyloidosis [68]. The main challenges are differentiating it from systemic amyloidosis, and local recurrences are common [69].

\section{Conclusions}

An early and accurate diagnosis of amyloidosis is the goal, and education efforts should be made to elicit awareness among internists, primary care providers, cardiologists, nephrologists, neurologists, and most importantly hematologists. 


\section{Statement of Ethics}

The patients gave their written informed consent.

\section{Disclosure Statement}

Dr. Gertz reports personal fees from Ionis/Akcea, personal fees from Alnylam, personal fees from Prothena, personal fees from Celgene, personal fees from Janssen, grants and personal fees from Spectrum, personal fees from Annexon, personal fees from Appellis, personal fees from Amgen, personal fees from Medscape, personal fees from Physicians Education Resource, personal fees for Data Safety Monitoring board from Abbvie, personal fees from Research to Practice, speaker fees from Teva, Speaker fees from Johnson and Johnson; Speaker fees from Medscape, Speaker fees DAVA oncology; Advisory Board for Pharmacyclics Advisory
Board for Proclara outside the submitted work; Development of educational materials for i3Health, Educational Program development i3Health, Royalties from Springer Publishing, Grant Funding Amyloidosis Foundation; International Waldenstrom Foundation.

\section{Funding Sources}

NCI SPORE MM SPORE 5P50 CA186781-04.

\section{Author Contributions}

I.V. wrote the first draft and approved the final version of the manuscript, M.G. wrote the first draft and approved the final version of the manuscript.

\section{References}

1 Merlini G, Bellotti V. Molecular mechanisms of amyloidosis. N Engl J Med. 2003 Aug; 349(6):583-96.

2 Benson MD, Buxbaum JN, Eisenberg DS, Merlini G, Saraiva MJM, Sekijima Y, et al. Amyloid nomenclature 2018: recommendations by the International Society of Amyloidosis (ISA) nomenclature committee. Amyloid. 2018;25(4):215-9.

3 Fernández de Larrea C, Verga L, Morbini P, Klersy C, Lavatelli F, Foli A, et al. A practical approach to the diagnosis of systemic amyloidoses. Blood. 2015 Apr;125(14):2239-44.

4 Gillmore JD, Maurer MS, Falk RH, Merlini G, Damy T, Dispenzieri A, et al. Nonbiopsy Diagnosis of Cardiac Transthyretin Amyloidosis. Circulation. 2016 Jun;133(24):2404-12.

5 Merlini G, Seldin DC, Gertz MA. Amyloidosis: pathogenesis and new therapeutic options. J Clin Oncol. 2011 May;29(14):192433.

6 Kyle RA, Linos A, Beard CM, Linke RP, Gertz MA, O'Fallon WM, et al. Incidence and natural history of primary systemic amyloidosis in Olmsted County, Minnesota, 1950 through 1989. Blood. 1992 Apr;79(7):1817-22.

7 Kyle RA, Larson DR, Kurtin PJ, Kumar S, Cerhan JR, Therneau TM, et al. Incidence of AL Amyloidosis in Olmsted County, Minnesota, 1990 through 2015. Mayo Clin Proc. 2019 Mar;94(3):465-71.

8 Quock TP, Yan T, Chang E, Guthrie S, Broder MS. Epidemiology of AL amyloidosis: a real-world study using US claims data. Blood Adv. 2018 May;2(10):1046-53.

9 Comenzo RL, Reece D, Palladini G, Seldin D, Sanchorawala V, Landau H, et al. Consensus guidelines for the conduct and reporting of clinical trials in systemic light-chain amyloidosis. Leukemia. 2012 Nov;26(11):2317-25.

10 Kumar S, Dispenzieri A, Lacy MQ, Hayman SR, Buadi FK, Colby C, et al. Revised prognostic staging system for light chain amyloidosis incorporating cardiac biomarkers and serum free light chain measurements. J Clin Oncol. 2012 Mar;30(9):989-95.

11 Staron A, Kataria Y, Murray DL, Sloan JM, Sanchorawala V. Systemic AL amyloidosis with an undetectable plasma cell dyscrasia: A zebra without stripes. Am J Hematol. 2020 Feb;95(2):E45-8.

12 ibrutinib (IMBRUVICA ${ }^{\circ}$ ) and Waldenström's macroglobulinaemia. Prescrire Int. 2016 Oct;25(175):232.

13 Milani P, Basset M, Russo F, Foli A, Merlini G, Palladini G. Patients with light-chain amyloidosis and low free light-chain burden have distinct clinical features and outcome. Blood. 2017 Aug;130(5):625-31.

14 McCausland KL, White MK, Guthrie SD, Quock T, Finkel M, Lousada I, et al. Light Chain (AL) Amyloidosis: The Journey to Diagnosis. Patient. 2018 Apr;11(2):207-16.

15 Muchtar E, Dispenzieri A, Lacy MQ, Buadi FK, Kapoor P, Hayman SR, et al. Overuse of organ biopsies in immunoglobulin light chain amyloidosis (AL): the consequence of failure of early recognition. Ann Med. 2017 Nov; 49(7):545-51.

16 Lousada I, Comenzo RL, Landau H, Guthrie S, Merlini G. Light Chain Amyloidosis: Patient Experience Survey from the Amyloidosis Research Consortium. Adv Ther. 2015 Oct;32(10):920-8.

17 Chee CE, Lacy MQ, Dogan A, Zeldenrust SR, Gertz MA. Pitfalls in the diagnosis of primary amyloidosis. Clin Lymphoma Myeloma Leuk. 2010 Jun;10(3):177-80.

18 Wechalekar AD, Schonland SO, Kastritis E, Gillmore JD, Dimopoulos MA, Lane T, et al. A European collaborative study of treatment outcomes in 346 patients with cardiac stage III AL amyloidosis. Blood. 2013 Apr;121(17): $3420-7$.

19 Muchtar E, Gertz MA, Kyle RA, Lacy MQ, Dingli D, Leung N, et al. A Modern Primer on
Light Chain Amyloidosis in 592 Patients With Mass Spectrometry-Verified Typing. Mayo Clin Proc. 2019 Mar;94(3):472-83.

20 Pinney JH, Whelan CJ, Petrie A, Dungu J, Banypersad SM, Sattianayagam P, et al. Senile systemic amyloidosis: clinical features at presentation and outcome. J Am Heart Assoc. 2013 Apr;2(2):e000098.

21 Geller HI, Singh A, Alexander KM, Mirto TM, Falk RH. Association Between Ruptured Distal Biceps Tendon and Wild-Type Transthyretin Cardiac Amyloidosis. JAMA. 2017 Sep;318(10):962-3.

22 Yanagisawa A, Ueda M, Sueyoshi T, Okada T, Fujimoto T, Ogi Y, et al. Amyloid deposits derived from transthyretin in the ligamentum flavum as related to lumbar spinal canal stenosis. Mod Pathol. 2015;28(2):201-7.

23 Sueyoshi T, Ueda M, Jono H, Irie H, Sei A, Ide $\mathrm{J}$, et al. Wild-type transthyretin-derived amyloidosis in various ligaments and tendons. Hum Pathol. 2011 Sep;42(9):1259-64.

24 Uotani K, Kawata A, Nagao M, Mizutani T, Hayashi $H$. Trigger finger as an initial manifestation of familial amyloid polyneuropathy in a patient with Ile107Val TTR. Intern Med. 2007;46(8):501-4.

25 Murtagh B, Hammill SC, Gertz MA, Kyle RA, Tajik AJ, Grogan M. Electrocardiographic findings in primary systemic amyloidosis and biopsy-proven cardiac involvement. Am J Cardiol. 2005 Feb;95(4):535-7.

26 Dubrey SW, Cha K, Anderson J, Chamarthi $\mathrm{B}$, Reisinger J, Skinner M, et al. The clinical features of immunoglobulin light-chain (AL) amyloidosis with heart involvement. QJM. 1998;91(2):141-57.

27 Gościniak P, Larysz B, Józwa R. Triple-trouble cardiomyopathy: myocardial infarction, diastolic heart failure, and conduction defects due to amyloidosis associated with multiple myeloma. Kardiol Pol. 2013;71(5): 543. 
28 Miani D, Rocco M, Alberti E, Spedicato L, Fioretti PM. Amyloidosis of epicardial and intramural coronary arteries as an unusual cause of myocardial infarction and refractory angina pectoris. Ital Heart J. 2002;3(8):47982.

29 Afzal A, Brener SJ, Narula N, Worku B, Gulkarov I. Cardiac Amyloidosis Presenting With Cardiogenic Shock. Am J Ther. 2016 Jul-Aug;23(4):e1060-3.

30 Siqueira-Filho AG, Cunha CL, Tajik AJ, Seward JB, Schattenberg TT, Giuliani ER. Mmode and two-dimensional echocardiographic features in cardiac amyloidosis. Circulation. 1981 Jan;63(1):188-96.

31 Pagourelias ED, Mirea O, Duchenne J, Van Cleemput J, Delforge M, Bogaert J, et al. Echo Parameters for Differential Diagnosis in Cardiac Amyloidosis: A Head-to-Head Comparison of Deformation and Nondeformation Parameters. Circ Cardiovasc Imaging. 2017 Mar; 10(3):e005588.

32 Bhatti S, Watts E, Syed F, Vallurupalli S, Pandey T, Jambekar K, et al. Clinical and prognostic utility of cardiovascular magnetic resonance imaging in myeloma patients with suspected cardiac amyloidosis. Eur Heart J Cardiovasc Imaging. 2016 Sep;17(9):970-7.

33 Vogelsberg H, Mahrholdt H, Deluigi CC, Yilmaz A, Kispert EM, Greulich S, et al. Cardiovascular magnetic resonance in clinically suspected cardiac amyloidosis: noninvasive imaging compared to endomyocardial biopsy. J Am Coll Cardiol. 2008 Mar;51(10):102230.

34 Gertz MA, Comenzo R, Falk RH, Fermand JP, Hazenberg BP, Hawkins PN, et al. Definition of organ involvement and treatment response in immunoglobulin light chain amyloidosis (AL): a consensus opinion from the 10th International Symposium on Amyloid and Amyloidosis, Tours, France, 18-22 April 2004. Am J Hematol. 2005 Aug;79(4):319-28.

35 Wang AK, Fealey RD, Gehrking TL, Low PA. Patterns of neuropathy and autonomic failure in patients with amyloidosis. Mayo Clin Proc. 2008 Nov;83(11):1226-30.

36 Lozeron P, Mariani LL, Dodet P, Beaudonnet G, Théaudin M, Adam C, et al. Transthyretin amyloid polyneuropathies mimicking a demyelinating polyneuropathy. Neurology. 2018 Jul;91(2):e143-52.

37 Youngstein T, Gilbertson JA, Hutt DF, Coyne MR, Rezk T, Manwani R, et al. Carpal Tunnel Biopsy Identifying Transthyretin Amyloidosis. Arthritis Rheumatol. 2017 Oct;69(10): 2051.

38 Sperry BW, Reyes BA, Ikram A, Donnelly JP, Phelan D, Jaber WA, et al. Tenosynovial and Cardiac Amyloidosis in Patients Undergoing Carpal Tunnel Release. J Am Coll Cardiol. 2018 Oct;72(17):2040-50.

39 Donnelly JP, Hanna M, Sperry BW, Seitz WH Jr. Carpal Tunnel Syndrome: A Potential Early, Red-Flag Sign of Amyloidosis. J Hand Surg Am. 2019 Oct;44(10):868-76.
40 Sugiyama A, Asahina M, Takeda Y, Shiojiri T, Sano K, Ikeda S, et al. Isolated autonomic failure without evident somatic polyneuropathy in AL amyloidosis. Amyloid. 2014;21(3):21820.

41 Tsourdi E, Därr R, Wieczorek K, Röcken C, Ehehalt F, Conrad K, et al. Macroglossia as the only presenting feature of amyloidosis due to MGUS. Eur J Haematol. 2014 Jan;92(1):88-9.

42 Jo G, Shin DY, Mun JH. Systemic amyloidosis-induced nail dystrophy. J Dtsch Dermatol Ges. 2019 Oct;17(10):1057-1059.

43 Xu J, Tahan S, Jan F, Do D, Wu H. Nail dystrophy as the initial sign of multiple myeloma-associated systemic amyloidosis. J Cutan Pathol. 2016 Jun;43(6):543-5.

44 Al Saleh AS, Sidiqi MH, Gertz MA. Joint Pain and Proteinuria. JAMA. 2019 Sep;322(15): 1512.

45 Agarwal A, Chang DS, Selim MA, Penrose CT, Chudgar SM, Cardones AR. Pinch Purpura: A Cutaneous Manifestation of Systemic Amyloidosis. Am J Med. 2015 Sep;128(9):e34.

46 Audemard A, Boutemy J, Galateau-Salle F, Macro M, Bienvenu B. AL amyloidosis with temporal artery involvement simulates giantcell arteritis. Joint Bone Spine. 2012 Mar; 79(2);195-7.

47 Lee AS, Lee DZ, Vasanwala FF. Amyloid light-chain amyloidosis presenting as abdominal bloating: a case report. J Med Case Reports. 2016 Mar; 10(1):68.

48 Menke DM, Kyle RA, Fleming CR, Wolfe JT 3rd, Kurtin PJ, Oldenburg WA. Symptomatic gastric amyloidosis in patients with primary systemic amyloidosis. Mayo Clin Proc. 1993 Aug;68(8):763-7.

49 Hoscheit M, Kamal A, Cline M. Gastroparesis in a Patient with Gastric AL Amyloidosis. Case Rep Gastroenterol. 2018 Jun;12(2):317-21.

50 Franck C, Venerito M, Weigt J, Roessner A, Malfertheiner P. Recurrent diffuse gastric bleeding as a leading symptom of gastrointestinal AL amyloidosis. Z Gastroenterol. 2017 Dec;55(12):1318-22.

51 Kim SY, Moon SB, Lee SK, Hong SK, Kim YH, Chae GB, et al. Light-chain amyloidosis presenting with rapidly progressive submucosal hemorrhage of the stomach. Asian J Surg. 2016 Apr;39(2):113-5.

52 Arahata M, Takamatsu H, Morishita E, Kadohira Y, Yamada S, Ichinose A, et al. Coagulation and fibrinolytic features in AL amyloidosis with abnormal bleeding and usefulness of tranexamic acid. Int J Hematol. 2020 Jan. https://doi.org/10.1007/s12185-019-02811-x.

53 Dejhansathit S, Suvannasankha A. Acquired Factor X Deficiency in Patients With Primary Light Chain Amyloidosis. J Investig Med High Impact Case Rep. 2019 Jan-Dec;7: 2324709619832332.

54 Lohana AK, Abid S, Sayani R, Tahir U, Shaikh PA. Hepatobiliary and Pancreatic: Bleeding in amyloid liver: A rare presentation of primary liver amyloidosis. J Gastroenterol Hepatol. 2019 Jun;34(6):965.
55 Harrison JS, Frazier SR, McConnell DD, Yasar SJ, Melnyk N, Salaru G. Evidence of both von Willebrand factor deposition and factor $\mathrm{V}$ deposition onto AL amyloid as the cause of a severe bleeding diathesis. Blood Coagul Fibrinolysis. 2017;28(4):342-7.

56 Qamar H, Lee A, Valentine K, Skeith L, Jimenez-Zepeda VH. Acquired von Willebrand Syndrome Associated to Secondary IgM MGUS Emerging after Autologous Stem Cell Transplantation for AL Amyloidosis. Mediterr J Hematol Infect Dis. 2017 May; 9(1):e2017034.

57 Dammacco R, Merlini G, Lisch W, Kivelä TT, Giancipoli E, Vacca A, et al. Amyloidosis and Ocular Involvement: an Overview. Semin Ophthalmol. 2020;35(1):7-26.

58 Muneeb A, Gupta S. Isolated Laryngeal Amyloidosis Mimicking Laryngeal Cancer. Cureus. 2018 Aug; 10(8):e3106.

59 Stavrakas M, Psillas G, Rachovitsas D, Triaridis S. Laryngeal Amyloidosis: An Interesting Presentation of Voice Quality Deterioration. Ear Nose Throat J. 2020;99(2):128-129.

60 Gallivan GJ, Gallivan HK. Laryngeal amyloidosis causing hoarseness and airway obstruction. J Voice 2010;24(2):235-9.

61 Gorospe L, Arrieta P, Barrios-Barreto D. Localized tracheal amyloidosis incidentally detected at lung cancer screening with low-dose thoracic CT. Rev Clin Esp. 2019 Dec;S00142565(19)30291-7.

62 Weidner T, Illing T, Elsner P. Primary Localized Cutaneous Amyloidosis: A Systematic Treatment Review. Am J Clin Dermatol. 2017 Oct;18(5):629-42.

63 Dokic Y, Subrt P, Tschen J. A Rare Presentation of Nodular Amyloidosis on the Lower Back. Cureus. 2019 Oct;11(10):e5864.

64 Smithee A, Garcia A, Tschen J, Schmidt J. Primary Localized Cutaneous Nodular Amyloidosis in the Absence of Systemic Disease. Skinmed. 2019 May;17(2):131-3.

65 Ogasawara N, Kitagawa W, Obayashi K, Itoh Y, Noda H, Funaki Y, et al. Solitary amyloidosis of the sigmoid colon featuring submucosal tumor caused hematochezia. Intern Med. 2013;52(22):2523-7.

66 Javed A, Canales BK, Maclennan GT. Bladder amyloidosis. J Urol. 2010 Jun;183(6):2388-9.

67 Cooper CT, Greene BD, Fegan JE, Rovira D, Gertz MA, Marcus DM. External beam radiation therapy for amyloidosis of the urinary bladder. Pract Radiat Oncol. 2018 Jan - Feb; 8(1):25-7.

68 Kourelis TV, Kyle RA, Dingli D, Buadi FK, Kumar SK, Gertz MA, et al. Presentation and Outcomes of Localized Immunoglobulin Light Chain Amyloidosis: The Mayo Clinic Experience. Mayo Clin Proc. 2017 Jun;92(6): 908-17.

69 Bartels H, Dikkers FG, van der Wal JE, Lokhorst HM, Hazenberg BP. Laryngeal amyloidosis: localized versus systemic disease and update on diagnosis and therapy. Ann Otol Rhinol Laryngol. 2004 Sep;113(9):741-8. 